\section{Impact of a High Phosphorus Fertilizer and Timing of Termination of Fertilization on Flowering of a Hybrid Moth Orchid}

\author{
Yin-Tung Wang ${ }^{1}$ \\ Department of Horticultural Sciences, Texas A\&M University System \\ Agricultural Research and Extension Center, 2415 East Highway 83, Weslaco, \\ TX 78596-8399
}

Additional index words. Phalaenopsis, moth orchid, floriculture, potted flowering plant, mineral nutrition, flower longevity

\begin{abstract}
An experiment was initiated to determine the effect of a low $\mathbf{N}$, high $\mathbf{P}$ and $\mathrm{K}$ fertilizer applied during the flowering season on a hybrid moth orchid (Phalaenopsis TAM Butterfly Blume.). On 1 Sept., plants of flowering size receiving $N, P$, and $K$ at 100,44 , and $83 \mathrm{mg} \cdot \mathrm{L}^{-1}$, respectively, from a $20 \mathrm{~N}-8.8 \mathrm{P}-16.6 \mathrm{~K}$ soluble fertilizer were given $\mathrm{N}, \mathrm{P}$, and $\mathrm{K}$, at 30,398 , and $506 \mathrm{mg} \cdot \mathrm{L}^{-1}$ (high $\left.\mathrm{P}\right)$, respectively, at each or every fourth irrigation. Control plants continued to receive the $20 \mathrm{~N}-8.8 \mathrm{P}-16.6 \mathrm{~K}$ fertilizer. The high $P$ treatments, regardless of the frequency of application, had no effect on the date of emergence of the flowering stem (spiking), anthesis, or flower size. All plants treated with the high $P$ fertilizer had fewer flowers (15 to 19) than the controls ( 24 flowers). Continuous application of adequate $N$ appears to be more important than low $N$ and increased $P$ for optimal flowering. In a separate experiment using the same hybrid orchid, terminating fertilization completely on 1 Sept., 29 Sept., or 27 Oct. or when the flowering stems were emerging (1 Oct.) reduced flower count $(\leq 19$ vs. 24). Flower longevity was reduced by $12 \mathrm{~d}$ when fertilization was terminated on 1 Sept. Flower size was unaffected by any treatment in either experiment. Discontinuing fertilization prior to late November reduced flower count. Withholding fertilization for extended periods resulted in red leaves, loss of the lower leaves, and limited production of new leaves.
\end{abstract}

Orchids are a specialty crop and they are produced mainly by people who have learned by experience. In the past, the market for potted orchids was primarily limited to hobbyists and people with higher income who could afford them. In recent years, use of orchids, particularly the hybrid Phalaenopsis, as potted flowering plants has increased dramatically, with a $50 \%$ increase in value from $\$ 47$ million in 1996 to \$70 million in 1997 (U.S. Dept. of Agriculture, 1998, 1999). A significant increase in the production of potted blooming orchids is expected in future years (Cosgrove, 1997).

Flowers of Phalaenopsis orchids are extremely long-lasting, staying in bloom for 4 months or longer (Wang, 1997), making them ideal pot plants. As the price has dropped steadily, more people have started purchasing potted blooming orchids. However, more information is needed for the development of a standard production procedure to follow for producers who do not have much prior experience growing potted orchids .

Received for publication 17 Aug. 1998. Accepted for publication 22 Mar. 1999. The excellent assistance of Lori L. Gregg is greatly appreciated.The cost of publishing this paper was defrayed in part by the payment of page charges. Under postal regulations, this paper therefore must be hereby marked advertisement solely to indicate this fact.

1Professor. E-mail address: yt-wang@tamu.edu
For many years, Douglas fir bark from the logging industry on the Pacific coast of the United States has been the primary medium for growing orchids in pots. Although Batchelor (1993) recommends a high nitrogen fertilizer (such as $30 \mathrm{~N}-4.4 \mathrm{P}-8.3 \mathrm{~K}$ ) during early production phase, followed by a high $\mathrm{P}$ fertilizer prior to flower initiation in early fall to improve reproductive growth, no research had been conducted to support this recommendation.

Phalaenopsis orchids planted in pure fir bark do not grow as well as those grown in improved media that promote leaf growth and flower production (Wang, 1995; Wang and Gregg, 1994). Orchid roots are sensitive to high salinity, and water high in dissolved salts tends to injure the roots (Wang, 1998), particularly in media containing peat, which also promotes growth (Wang, 1995). Since high fertilizer rates are needed during the warm spring and summer to promote vegetative growth, reduced fertility may be needed in the early fall to avoid root injury due to limited or no vegetative growth and reduced nutrient uptake during the cooler period of the year. Reducing the rate of fertilization or terminating fertilization completely near the end of the production cycle improves the postproduction keeping quality of poinsettia (Euphorbia pulcherrima Willd.) (Biernbaum et al., 1992; Nell and Barrett, 1986). However, the effects of similar practices on flowering of potted or- chids must be determined so that plant quality is not compromised.

The objectives of this study were to determine the long-term effects of reduced fertilizer application and the use of a low $\mathrm{N}$, high $\mathrm{P}$ and $\mathrm{K}$ fertilizer in the fall on reproductive performance and flower longevity of a hybrid Phalaenopsis orchid.

\section{Materials and Methods}

Twenty-month-old (from the time of seed sowing) Phalaenopsis TAM Butterfly seedling plants of flowering size were transplanted in early April into $1.75-\mathrm{L}$ (15.2 cm diameter and $14 \mathrm{~cm}$ tall) plastic pots containing $80 \%$ fine-grade Douglas fir bark and 20\% Canadian sphagnum peat (by volume). The medium was amended with $1.5 \mathrm{~kg}$ powdered dolomitic limestone and $0.5 \mathrm{~kg}$ of Micromax (amicronutrient source; Grace-Sierra, Milpitas, Calif.) per $\mathrm{m}^{3}$. Plants were grown in a greenhouse with a maximum photosynthetic photon flux $(P P F)$ of $300 \mu \mathrm{mol} \cdot \mathrm{m}^{-2} \cdot \mathrm{s}^{-1}$ and given $\mathrm{N}, \mathrm{P}$, and $\mathrm{K}$ at 100,44 , and $83 \mathrm{mg} \cdot \mathrm{L}^{-1}$, respectively, from a water-soluble Peters $20 \mathrm{~N}-8.8 \mathrm{P}-16.6 \mathrm{~K}$ fertilizer $\left(0.5 \mathrm{~g} \cdot \mathrm{L}^{-1}\right.$; Scotts, Inc., Marysville, Ohio) at each irrigation with municipal water that had an electrical conductivity of 1.4 $\mathrm{dS} \cdot \mathrm{m}^{-1}$. On 1 Sept., the uppermost leaf on each plant was marked for later determination of new leaf production.

High $P$ and $K$ fertilization. Treatments were initiated on 1 Sept. The high $\mathrm{P}$ and $\mathrm{K}$ fertilizer was prepared by mixing $0.25 \mathrm{~g}$ of $\mathrm{Ca}\left(\mathrm{NO}_{3}\right)_{2} \cdot 4 \mathrm{H}_{2} \mathrm{O}$ and $1.75 \mathrm{~g}$ of $\mathrm{KH}_{2} \mathrm{PO}_{4}$ in $1 \mathrm{~L}$ of water. This solution provided $30 \mathrm{mg} \mathrm{N}(2.14$ $\left.\mathrm{mmol} \cdot \mathrm{L}^{-1}\right), 398 \mathrm{mg} \mathrm{P}\left(12.6 \mathrm{mmol} \cdot \mathrm{L}^{-1}\right), 506 \mathrm{mg}$ $\mathrm{K}\left(12.9 \mathrm{mmol} \cdot \mathrm{L}^{-1}\right)$, and $42 \mathrm{mg} \mathrm{Ca}(1.06$ $\left.\mathrm{mmol} \cdot \mathrm{L}^{-1}\right)$ per liter. Peters $20 \mathrm{~N}-4.4 \mathrm{P}-8.3 \mathrm{~K}$ fertilizer contains $\approx 12 \%$ urea as its $\mathrm{N}$ source, whereas the low $\mathrm{N}$, high $\mathrm{P}$ and $\mathrm{K}$ fertilizer does not contain urea. Plants received either continuous high $\mathrm{P}(\mathrm{PP})$ or the high $\mathrm{P}$ fertilization followed by three irrigations with municipal water (PW). Controls continued to receive the Peters fertilizer at every irrigation. Plants were irrigated at irregular intervals, depending upon weather conditions. At each irrigation, 240 $\mathrm{mL}$ of fertilizer solution was applied to each pot. A single plant in a pot constituted an experimental unit and treatments were replicated 20 times in a randomized completeblock design. This high number of replications was deemed necessary for increased precision and accuracy because of the use of seedling plants.

Termination of fertilization. Fertilization was terminated either by date at 4-week intervals (1 Sept., 29 Sept., 27 Oct., or 24 Nov.) or by developmental stage [at first spiking (no flower primordia), spikes $10 \mathrm{~cm}$ in length (partial initiation of flower primordia), or at the opening of the first flower]. Fertilizer was withheld from each plant when it had reached its designated developmental stage. Only municipal water was applied following the termination of fertilization. Plants that continuously received the Peters fertilizer served as controls. A single pot represented an experimental unit and treatments were replicated 25 
times in a randomized complete-block design.

Dates of spiking and opening of the first flower, flower diameter, total flower count, and leaf number were recorded for each plant. The date on which the first flower started to wither was recorded for determining flower longevity. Data were subjected to analysis of variance and Tukey's HSD was used for multiple range mean separation.

\section{Results and Discussion}

Neither treatment PP nor PW affected the dates of spiking and flower opening (Table 1). However, the low N, high $\mathrm{P}$ and $\mathrm{K}$ fertilizer, regardless of the frequency of application, reduced flower count (Table 1), but did not affect flower longevity. The PW treatment resulted in 10 fewer flowers per plant than did application of Peters fertilizer at much lower rates of $\mathrm{P}$ and $\mathrm{K}$. In a previous study (Wang and Gregg, 1994), as the rate of a $20 \mathrm{~N}-8.6 \mathrm{P}-$ $16.6 \mathrm{~K}$ fertilizer increased from 0.25 to 1.0 $\mathrm{g} \cdot \mathrm{L}^{-1}$, after over 1 year of application, plants bloomed progressively earlier, with increasing flower counts (Wang and Gregg, 1994). On the contrary, Kubota and Yoneda (1994) found in a short-term study that large plants given a complete fertilizer from April to September did not produce more flowers than those that received the same fertilizer during April and May, but were not given $\mathrm{N}$ between June and September. Their extremely low flower counts, the relatively short treatment period, and the use of sphagnum moss as the sole potting medium may have masked any possible effects of the reduced $\mathrm{N}$ application.

Plants in PP and PW treatments had fewer leaves than the controls (Table 1) at the termination of this experiment as a result of both slower production of new leaves and the accelerated abscission of lower leaves. That increased rate of fertilizer promotes vegetative growth is well documented (Kubota and Yoneda, 1994; Lee and Lin, 1987; Wang and Gregg, 1994). Wang (1996) determined that higher concentration of $\mathrm{N}$ is more critical than $\mathrm{P}$ or $\mathrm{K}$ in promoting vegetative growth in a medium consisting of $80 \%$ Douglas fir bark and $20 \%$ peat.

When moth orchids are grown in pure Douglas fir bark, applying a fertilizer high in $\mathrm{P}$ in the early fall is recommended to promote flowering (Batchelor, 1993; Gordon, 1990). However, when plants were grown in the same mix as the one used in the current study and given $\mathrm{N}$ at $200 \mathrm{mg} \cdot \mathrm{L}^{-1}, \mathrm{P}$ at levels between 22 and $262 \mathrm{mg} \cdot \mathrm{L}^{-1}$ and $\mathrm{K}$ at levels between 152 and $332 \mathrm{mg} \cdot \mathrm{L}^{-1}$ from various soluble fertilizers, no differences in vegetative growth and flower production were observed (Wang, 1996). In the current study, the low $N$, high $P$ and $\mathrm{K}$ fertilizer reduced flower count, rather than increasing it (Table 1). Therefore, continuous application of an adequate level of $\mathrm{N}$ may be more important than increased $\mathrm{P}$ for optimal flowering. The concentration of $\mathrm{N}$ (30 $\mathrm{mg} \cdot \mathrm{L}^{-1}$ ) in this high $\mathrm{P}$ and $\mathrm{K}$ fertilizer did not appear to be sufficient to maintain a high flower count in the warm climate where this study was conducted. Most potted Phalaenopsis are produced in states with warm climates (U.S. Dept. of Agriculture, 1998).

Terminating fertilization completely on any date or at any stage of development had no impact on the date of spiking and anthesis or on flower size (Table 2). All plants flowered between 9 and 17 Jan., with flowers averaging $10.5 \mathrm{~cm}$ in diameter. Discontinuing fertilizer application in September and October reduced flower count (Table 2). Flower longevity was reduced more when fertilization was discontinued on 1 Sept. than when discontinued later. When fertilization was terminated during the early stages of inflorescence development, plants had fewer leaves, mainly as a result of abscission of lower leaves, at the end of this experiment.

Using a hybrid Phalaenopsis orchid, Lee and Lee (1996) found that a flowering stem starts to initiate its first floral primordium when it is only $3.5 \mathrm{~cm}$ in length. Plants used in the current experiments started spiking on 1 Oct. By 24 Nov., the flowering stems were $>15 \mathrm{~cm}$ in length and most of the flower primordia should have been differentiated (Lee and Lee, 1996). In addition, plants were irrigated infrequently in late fall and the nutrients applied previously may have stayed in the medium for some time following the termination of fertilizer application. Using peat-based media, Argo and Biernbaum (1995) found that nutrients in the root zone of container-grown poinsettia remained at acceptable levels for 42 $\mathrm{d}$ after fertilization was terminated. Therefore, discontinuing fertilization at this advanced stage of inflorescence development had no adverse effect on flower count of Phalaenopsis (Table 2). The results of this study indicate that maintaining a relatively high concentration of $\mathrm{N}$ fertilizer before and after spiking until near completion of floral bud initiation is crucial to sustaining the initiation of floral primordia, resulting in a high flower count.

That the size of the first flowers on inflorescences did not change in either experiment, regardless of reduced nutrient application, is rather surprising. Nutrients in the lower leaves may have been remobilized for production of flowers. Since flower size near the tips of the inflorescences was not measured, we do not know how discontinuing fertilization at any stage would have affected the size of such flowers.

Leaves of plants that received no fertilizer after 1 Sept. were less green, with the highest degree of red pigmentation and more abscission of the older leaves, indicating that they were under severe nutrient stress, as described by Mengel and Kirkby (1982). As fertilization was discontinued at progressively later dates, this red pigmentation decreased and the green intensified, suggesting increased chlorophyll levels. Since Phalaenopsis orchids have relatively few leaves, they must be given proper levels of nutrients to keep the lower leaves from abscising.

\section{Literature Cited}

Argo, W.R. and J.A. Biernbaum. 1995. Root-medium nutrient levels and irrigation requirements of poinsettias grown in five root media. J. Amer. Soc. Hort. Sci. 30:535-538.

Table 1. Effects of continuing high $\mathrm{N}$ fertilizer or application of a low $\mathrm{N}$, high $\mathrm{P}$ and $\mathrm{K}$ fertilizer at various frequencies (at every irrigation, PP, or at every fourth irrigation, $\mathrm{PW}$ ) on performance of the Phalaenopsis orchids. Flower longevity was recorded for the basipetal first flower on each inflorescence.

\begin{tabular}{|c|c|c|c|c|c|c|}
\hline \multirow{3}{*}{$\begin{array}{l}\text { Fertilizer } \\
\text { treatment }^{\mathrm{z}}\end{array}$} & & & \multicolumn{2}{|c|}{ Flower } & \multirow{3}{*}{$\begin{array}{c}\text { Leaf } \\
\text { no. }\end{array}$} & \multirow{3}{*}{$\begin{array}{c}\text { Total } \\
\text { flower } \\
\text { no. }\end{array}$} \\
\hline & \multicolumn{2}{|c|}{ Date of: } & Diam & Longevity & & \\
\hline & Spiking & $\overline{\text { Anthesis }}$ & $(\mathrm{cm})$ & (d) & & \\
\hline Continuous high $\mathrm{N}$ & 12 Oct. $a^{y}$ & 23 Jan. a & $10.5 \mathrm{a}$ & $93 \mathrm{a}$ & $6.5 \mathrm{a}$ & $25.2 \mathrm{a}$ \\
\hline $\mathrm{PP}$ & 6 Oct. a & 16 Jan. a & $10.7 \mathrm{a}$ & $85 \mathrm{a}$ & $5.0 \mathrm{~b}$ & $18.6 \mathrm{~b}$ \\
\hline PW & 8 Oct. a & 15 Jan. a & $10.8 \mathrm{a}$ & $85 \mathrm{a}$ & $4.5 \mathrm{~b}$ & $15.0 \mathrm{c}$ \\
\hline
\end{tabular}

${ }^{\mathrm{z}}$ High $\mathrm{N}=$ Peters $20 \mathrm{~N}-8.7 \mathrm{P}-16.6 \mathrm{~K}$ soluble fertilizer at 100,43 , and $83 \mathrm{mg} \cdot \mathrm{L}^{-1}$ of $\mathrm{N}, \mathrm{P}$, and $\mathrm{K}$, respectively. $\mathrm{P}=$ low $\mathrm{N}$, high $\mathrm{P}$ and $\mathrm{K}$ fertilizer at 30,390 , and $506 \mathrm{mg} \cdot \mathrm{L}^{-1}$ of $\mathrm{N}, \mathrm{P}$, and $\mathrm{K}$, respectively. $\mathrm{W}=$ water with no fertilizer.

'Mean separation within columns by Tukey's HSD, $P \leq 0.05$.

Table 2. Effects of terminating fertilization at various dates or developmental stages on performance of Phalaenopsis orchids. Flower longevity was recorded for the basipetal first flower on each inflorescence.

\begin{tabular}{|c|c|c|c|c|c|c|}
\hline \multirow{3}{*}{$\begin{array}{l}\text { Fertilizer } \\
\text { termination } \\
\text { date }^{z}\end{array}$} & & & \multicolumn{2}{|c|}{ Flower } & \multirow{3}{*}{$\begin{array}{c}\text { Flower } \\
\text { no. }\end{array}$} & \multirow{3}{*}{$\begin{array}{c}\text { Leaf } \\
\text { no. }\end{array}$} \\
\hline & \multicolumn{2}{|c|}{ Date of: } & \multirow{2}{*}{$\begin{array}{c}\text { Longevity } \\
\text { (d) }\end{array}$} & \multirow{2}{*}{$\begin{array}{l}\text { Diam } \\
(\mathrm{cm})\end{array}$} & & \\
\hline & Spiking & Anthesis & & & & \\
\hline \multicolumn{7}{|c|}{ By date } \\
\hline 1 Sept. & 30 Sept. $a^{y}$ & 17 Jan. a & $91 \mathrm{~b}$ & $10.7 \mathrm{a}$ & $16.0 \mathrm{c}$ & $4.1 \mathrm{c}$ \\
\hline 29 Sept. & 30 Sept. a & 13 Jan. a & $96 a b$ & $10.4 \mathrm{a}$ & $20.4 \mathrm{~b}$ & $4.8 \mathrm{bc}$ \\
\hline 27 Oct. & 3 Oct. a & 17 Jan. a & $97 \mathrm{ab}$ & $10.8 \mathrm{a}$ & $18.0 \mathrm{bc}$ & $4.6 \mathrm{bc}$ \\
\hline 24 Nov. & 2 Oct. a & 14 Jan. a & $95 \mathrm{ab}$ & $10.4 \mathrm{a}$ & $24.8 \mathrm{a}$ & $5.0 \mathrm{~b}$ \\
\hline Continuous & 30 Sept. a & 12 Jan. a & $103 \mathrm{a}$ & $10.6 \mathrm{a}$ & $24.4 \mathrm{a}$ & $5.7 \mathrm{a}$ \\
\hline \multicolumn{7}{|c|}{ By developmental stage } \\
\hline At spiking & 1 Oct. a & 9 Jan. a & $96 \mathrm{a}$ & $10.5 \mathrm{a}$ & $19.0 \mathrm{~b}$ & $5.0 \mathrm{~b}$ \\
\hline 10-cm spike & 9 Oct. a & 12 Jan. a & $92 \mathrm{a}$ & $10.4 \mathrm{a}$ & $21.0 \mathrm{ab}$ & $4.9 \mathrm{~b}$ \\
\hline 1st flower opening & 1 Oct. a & 9 Jan. a & $92 \mathrm{a}$ & $10.5 \mathrm{a}$ & $20.8 \mathrm{ab}$ & $5.3 \mathrm{ab}$ \\
\hline Continuous & 30 Sept. a & 12 Jan. a & $103 \mathrm{a}$ & $10.6 \mathrm{a}$ & $24.4 \mathrm{a}$ & $5.7 \mathrm{a}$ \\
\hline
\end{tabular}

zThe $20 \mathrm{~N}-8.7 \mathrm{P}-16.6 \mathrm{~K}$ fertilizer was used at $0.5 \mathrm{~g} \cdot \mathrm{L}^{-1}$.

y Mean separation within columns and dates/stages by Tukey's HSD, $P \leq 0.05$. 
Batchelor, S.R. 1993. Your first orchid. Amer. Orchid Soc. Bul. 62(3):258-261.

Biernbaum, J.A., M. Yelanich, and B. Argo. 1992. How much fertilizer should you apply? Greenhouse Grower 10(8):56-58.

Cosgrove, T. 1997. Creating a mass. Greenhouse Prod. News 7(11):24-27.

Gordon, B. 1990. Culture of Phalaenopsis. Laidback Publ., Rialto, Calif.

Kubota, S. and K. Yoneda. 1994. Effect of timing of nitrogen application on growth and flowering in Phalaenopsis plant. Trop. Agr. 38(1):73-77.

Lee, N. and C.H.Lee. 1996. Changes in Phalaenopsis during flower induction and inflorescence development. J. Chinese Soc. Hort. Sci. 42:262-275.

Lee, N. and G.M. Lin. 1987. Controlling the flower- ing of Phalaenopsis. Symp. on Forcing Culture of Hort. Crops. L.R. Chang (ed.) Special Publ. No. 10 of Taichung District Agr. Improvement Sta., Changhua, Taiwan, R.O.C.

Mengel, K. and E.A. Kirkby. 1982. Principles of plant nutrition. Intl. Potash Inst., WorblaufenBern, Switzerland.

Nell, T.A. and J.E. Barrett. 1986. Growth and influence of bract necrosis in 'Gutbier V-14 Glory' poinsettia. J. Amer. Soc. Hort. Sci. 111:266269.

U.S. Dept. of Agriculture. 1998. Floriculture statistics 1997. U.S. Dept. Agr., Washington, D.C.

U.S. Dept. of Agriculture. 1999. Floriculture statistics 1998. U.S. Dept. Agr., Washington, D.C.

Wang, Y.T. 1995. Medium and fertilization affect performance of potted Dendrobium and Phalaenopsis. HortTechnology 5:234-237.

Wang, Y.T. 1996. Effect of six fertilizers on vegetative growth and flowering of Phalaenopsis orchids. Scientia Hort. 65:191-197.

Wang, Y.T. 1997. Phalaenopsis light requirements and scheduling of flowering. Orchids 66:934 939.

Wang, Y.T. 1998. Impact of salinity and media on growth, flowering, and leaf mineral concentration of a hybrid Phalaenopsis orchid. HortScience 33:247-250.

Wang, Y.T. and L.L. Gregg. 1994. Medium and fertilizer affect the performance of Phalaenopsis orchids during two flowering cycles. HortScience 29:269-271 